\title{
Emociones, preocupaciones y reflexiones frente a la pandemia del COVID-19 en Argentina
}

\author{
Emotions, concerns and reflections regarding the COVID-19 \\ pandemic in Argentina
}

\begin{abstract}
María Cecilia Johnson (https://orcid.org/0000-0002-5102-2504) ${ }^{1}$
Lorena Saletti-Cuesta (https://orcid.org/0000-0002-0989-4093) ${ }^{2}$

Natalia Tumas (https://orcid.org/0000-0003-4730-6624) ${ }^{3}$
\end{abstract}

${ }^{1}$ Centro de Investigaciones y Estudios sobre Cultura y Sociedad, Universidad Nacional de Córdoba. Av. Ciudad de Valparaíso $\mathrm{s} / \mathrm{n}$, Ciudad Universitaria. Córdoba Argentina.

cecilia.johnson@unc.edu.ar ${ }^{2}$ Facultad de Ciencias Médicas, Universidad Nacional de Córdoba. Córdoba Argentina.

${ }^{3}$ Facultad de Ciencias de la Salud, Universidad Católica de Córdoba. Córdoba Argentina.

\begin{abstract}
The scope of this work is to explore the feelings and expectations that COVID-19 has generated in Argentina during the first stage of the pandemic. A survey of the World Health Organization adapted to the local context was applied. Open-ended questions were included to study people's feelings about COVID-19, and content analysis was subsequently conducted. In terms of results, it is revealed that the population surveyed feels uncertainty, fear and anguish, albeit a feeling of responsibility and care in the face of COVID-19 also emerges. Moreover, positive feelings regarding society stand out as an achievement of social interdependence. The results obtained show that the impact on mental health differs in accordance with gender, educational level, and perceived comfort in the home. The study concludes that the emotional and bonding dimensions of people are central to confronting the COVID-19 pandemic in Argentina. It is recommended that these dimensions, as well as their subjective and differential social impact among the different population groups, should be considered in the planning of policies to address the COVID-19 pandemic.

Key words Mental health, Coronavirus, Pandemic, Emotions, Health impact assessment
\end{abstract}

Resumen El objetivo de este trabajo es explorar los sentimientos y expectativas que genera el COVID-19 en Argentina durante la primera etapa de la pandemia. Se aplicó una encuesta de la Organización Mundial de la Salud adaptada al contexto local. Se incluyeron preguntas abiertas para indagar sentimientos de las personas frente al COVID-19, y se realizó un análisis de contenido. Como resultados se advierte que la población encuestada siente incertidumbre, miedo y angustia, pero también emerge un sentimiento de responsabilidad y cuidado frente al COVID-19. Así mismo se destacan sentimientos positivos para la sociedad como una valoración de la interdependencia social. Los resultados arribados señalan que el impacto en la salud mental es desigual según el género, el nivel educativo alcanzado y el confort percibido en el hogar. El estudio permite concluir que las dimensiones emocionales y vinculares de las personas resultan aspectos centrales ante la pandemia del COVID-19 en Argentina. Es recomendable que estas dimensiones, así como y su impacto subjetivo y social diferencial entre los diversos grupos poblacionales, sean consideradas en la planificación de politicas para afrontar el COVID-19.

Palabras clave Salud mental, Coronavirus, Pandemia, Emociones, Evaluación del impacto en la salud 


\section{Introducción}

A finales del 2019, se identificó en China un nuevo coronavirus al que se lo denominó COVID-19. Debido a su velocidad de expansión y gravedad, el 11 de marzo-2020, la Organización Mundial de la Salud (OMS) lo declaró como pandemia ${ }^{1}$.

En Argentina el primer caso confirmado fue el 5 de marzo-2020. Desde entonces el número de contagios aumenta rápidamente, y se implementan diversas medidas para su prevención, siendo el aislamiento social preventivo y obligatorio, desde el 20 de marzo-2020, la de mayor impacto social.

Un evento tan disruptivo genera diversos efectos en la salud de la población. Aún no existen vacunas ni tratamientos efectivos, se desconoce la duración de las medidas de aislamiento, y se estima un alto impacto económico, social y sanitario, lo que aumenta aún más la incertidumbre. En toda pandemia es esperable que las personas sientan miedo, ansiedad, angustia, irritabilidad, estrés y enojo, recuerdo de traumas, dificultades para la concentración y/o problemas en el sueño ${ }^{2}$.

Para abordar el impacto en la salud mental, ya en 2006 la Unidad de Salud Mental de la Organización Panamericana de la Salud elaboró un documento técnico para orientar y guiar las acciones en el campo de la salud mental en contexto de epidemias. Recientemente, ante el COVID-19, la $\mathrm{OMS}^{3}$ elaboró una serie de mensajes para apoyar el bienestar mental y psicosocial orientado a diferentes grupos. Por ejemplo, recomienda buscar información en fuentes confiables, indagar historias positivas de personas que se ha recuperado del COVID-19, o mantener rutinas diarias. En nuestro contexto, el Ministerio de Salud de la Nación ha elaborado diversas recomendaciones para reducir el impacto en la salud mental ${ }^{4}$.

Trabajos recientes advierten sobre las consecuencias en la salud mental que el COVID-19 y el aislamiento social provocan en la población ${ }^{5,6}$. En este sentido, en China el 53,8\% de personas clasificó el impacto psicológico del COVID-19 como moderado o severo ${ }^{7}$. Asimismo, en se identificó como grupos más vulnerables a quienes deberían dirigirse los apoyos psicoterapéuticos a: personas infectadas y quienes tienen vínculos cercanos con ellas, personas con condiciones previas de padecimiento mental y subjetivo, y personal del sistema de salud ${ }^{8}$. Estos tres grupos también fueron señalados por Inchausti et al. ${ }^{9}$ quienes, además destacan la importancia de identificar riesgos y ofrecer intervenciones psicoterapéuticas flexibles y dinámicas ante las diferentes fases de la pandemia.

En China se ha implementado atención psicológica de emergencia para paliar el impacto en la salud mental ante el COVID-19 ${ }^{10}$. Sin embargo, Duan y $\mathrm{Zhu}^{11}$ advierten falencias en la atención psicológica brindada ante la pandemia. En Singapur, también se destaca la falta de planificación y coordinación para organizar la atención psicológica ante el COVID-19 y advierten la influencia de los medios masivos de comunicación $y$ las redes sociales en la salud mental ${ }^{12}$.

$\mathrm{La} \mathrm{OMS}^{13}$ ha advertido que el impacto en la salud mental de una epidemia, generalmente, es más fuerte entre quienes viven en situación de exclusión social o las personas mayores. En este marco, resulta importante reconocer las diferencias de vulnerabilidad de los distintos grupos poblacionales, en especial las relacionadas con el género, la edad, y el nivel socio-económico.

Atender el impacto de la pandemia en la salud mental es importante no solo para mejorar la salud sino también para evitar otros problemas sociales, tales como la estigmatización de personas, la falta de adherencia a medidas de prevención, y el duelo frente a la pérdida de seres queridos. En definitiva, estos factores tienen un rol fundamental para afrontar la pandemia de manera integral ${ }^{2}$.

Atendiendo al impacto social y subjetivo que el COVID-19 produce a nivel global, este trabajo se propone como objetivo explorar los sentimientos y expectativas que genera el COVID-19 en las personas durante la primera etapa de la pandemia en Argentina.

\section{Metodología}

\section{Diseño del estudio y recolección de datos}

Este estudio transversal implementado en Argentina sigue la propuesta del estudio "COVID-19 Snapshot MOnitoring (COSMO):Monitoring knowledge, risk perceptions, preventive behaviours, and public trust in the current coronavirus outbreak"14, elaborado por la Oficina Regional Europea de la OMS. Adopta la modalidad de recolección de datos en fases u olas para obtener información en distintos momentos de la situación epidemiológica.

Los datos fueron recolectados a través de un cuestionario diseñado por dicho estudio y adaptado al contexto argentino. En este sentido, el instrumento que fue traducido al castellano, y se 
incorporaron las medidas preventivas vigentes en nuestro contexto. Además, se diseñó el cuestionario en la plataforma de Google Forms.

La primera versión del cuestionario traducido y adaptado fue revisada por el equipo de investigación y se consultó a personas expertas. Una versión preliminar fue testeada mediante envío a una muestra de conveniencia de 30 personas. Finalmente, la versión argentina del cuestionario excluyó algunas secciones del original que no resultaron comprensibles o aceptables en la prueba piloto y sumó otras variables. Entre ellas, se agregaron dos preguntas de respuesta abierta para indagar impacto emocional del COVID-19 y las expectativas vinculadas al impacto social: 1 . Menciona las tres primeras palabras o ideas que se le vienen a la cabeza sobre los sentimientos que le genera el nuevo coronavirus; 2 . Menciona las tres primeras palabras o ideas que se le vienen a la cabeza sobre las consecuencias positivas que podría tener el coronavirus en nuestra sociedad.

La primera implementación del cuestionario se distribuyó en población mayor de 18 años y residentes en Argentina, a través redes sociales durante 48 horas, entre el 23 y el 25 de marzo-2020. Esta primera medición coincidió con el informe realizado por el Ministerio de Salud del primer caso probable de transmisión local de COVID-19. La segunda implementación se distribuyó de la misma manera a una muestra independiente de la ola anterior. La misma se inició el 30 de marzo-2020, un día después del anuncio de ampliación de los días de aislamiento social, y finalizó el 3 de abril.

Se realizó un muestreo aleatorio estratificado, acorde a la distribución por edad y sexo de la población argentina. En la primera ola la muestra final quedó conformada por 992 personas y en la segunda por 418 personas. Los datos se recopilaron online de forma anónima y cada participante brindó su consentimiento informado al comenzar el cuestionario. Al finalizar se brindó el enlace a la web del Ministerio de Salud de la Nación para ofrecer información nacional confiable y válida sobre COVID-19.

\section{Análisis de datos}

Para las dos preguntas de respuesta abierta se realizó un análisis de contenido ${ }^{15}$. En primer lugar, se realizó un análisis de frecuencia de palabras para cada pregunta y momento de recolección de datos. Todos los datos fueron leídos por una investigadora de forma repetida para obtener una comprensión clara del conjunto de datos. A partir de ello, formuló un primer esquema de codificación de forma inductiva. Este esquema fue discutido con una segunda investigadora. Posteriormente se prosiguió a la codificación de los datos que fue revisada por ambas investigadoras. Luego, los códigos se clasificaron en categorías en función de cómo los diferentes códigos estaban relacionados y vinculados. Estas categorías emergentes se utilizaron para organizar y agrupar códigos en grupos significativos. Posteriormente, en cada ola, se procedió a analizar los temas y subtemas con distintas variables sociodemográficas para indagar diferencias y similitudes. El análisis se realizó por separado para cada pregunta y utilizando el software NVivo 12.

\section{Resultados}

La tasa de respuesta a las dos preguntas abiertas fue muy alta en ambas olas. Las principales características sociodemográficas de la muestra se detallan en la Tabla 1.

El análisis de frecuencia de palabras de la primera pregunta, en las distintas olas, se refleja en el Gráfico 1. A mayor tamaño de la fuente, mayor recurrencia de la palabra. Desde una mirada global, los sentimientos más mencionados son miedo, incertidumbre y preocupación. En relación a la segunda pregunta, el análisis de frecuencia indica que las palabras que aparecen con mayor frecuencia fueron: Solidaridad y Conciencia (Gráfico 2).

A continuación, se detallan los principales temas y subtemas identificados.

\section{Sentimientos frente al COVID-19}

Este tema agrupa diversos sentimientos generados por la pandemia, donde destacan principalmente la incertidumbre, el miedo y la angustia. A continuación, desarrollaremos estos subtemas.

El subtema más relevante que aparece en ambos momentos de toma de datos es el denominado Incertidumbre que expresa un sentimiento generalizado de preocupación en la población. Por un lado, este sentimiento se vincula a una situación incierta, propia del contexto de pandemia, que es indefinida y que no permite planificación. Surgen expresiones como: Incertidumbre respecto al futuro próximo y de mediano plazo (Ola 1, mujer, 62 años) o Mucha impotencia por tanta gente enferma [...] y miedo por todos y no saber cuándo va a terminar esto (Ola 2, mujer, 48 años). Esta in- 
Tabla 1. Características sociodemográficas de las personas que respondieron las preguntas abiertas sobre COVID-19, Argentina, 2020.

\begin{tabular}{|c|c|c|c|c|}
\hline \multirow[b]{2}{*}{ Variables } & \multicolumn{2}{|c|}{$1^{\circ}$ ola de encuestas } & \multicolumn{2}{|c|}{$2^{\circ}$ ola de encuestas } \\
\hline & $\begin{array}{l}\text { Sentimientos } \\
\text { que genera el } \\
\text { COVID-19 }\end{array}$ & $\begin{array}{l}\text { Consecuencias } \\
\text { positivas del } \\
\text { COVID-19 }\end{array}$ & $\begin{array}{l}\text { Sentimientos } \\
\text { que genera el } \\
\text { COVID-19 }\end{array}$ & $\begin{array}{c}\text { Consecuencias } \\
\text { positivas del } \\
\text { COVID-19 }\end{array}$ \\
\hline $\mathbf{N}$ & 945 & 397 & 917 & 388 \\
\hline Mujeres (\%) & 51,43 & 50,88 & 51,91 & 50,52 \\
\hline Edad (media y desviación standard) & $41,69(15,95)$ & $41,54(15,18)$ & $41,55(15,88)$ & $41,48(15,05)$ \\
\hline $\begin{array}{l}\text { Nivel educativo ( } \% \text { con universitario } \\
\text { completo y postgrado) }\end{array}$ & 48,57 & 47,36 & 47,98 & 48,97 \\
\hline Salud percibida (\% muy buena o excelente) & 69,81 & 69,02 & 69,47 & 69,07 \\
\hline Grupo de riesgo frente a COVID-19 (\% sí) & 26,35 & 26,01 & 25,95 & 26,11 \\
\hline $\begin{array}{l}\text { Percepción de confort de su hogar en } \\
\text { situación de aislamiento ( } \% \text { mucha } \\
\text { comodidad y comodidad) }\end{array}$ & 69,52 & 69,52 & 74,57 & 69,33 \\
\hline
\end{tabular}
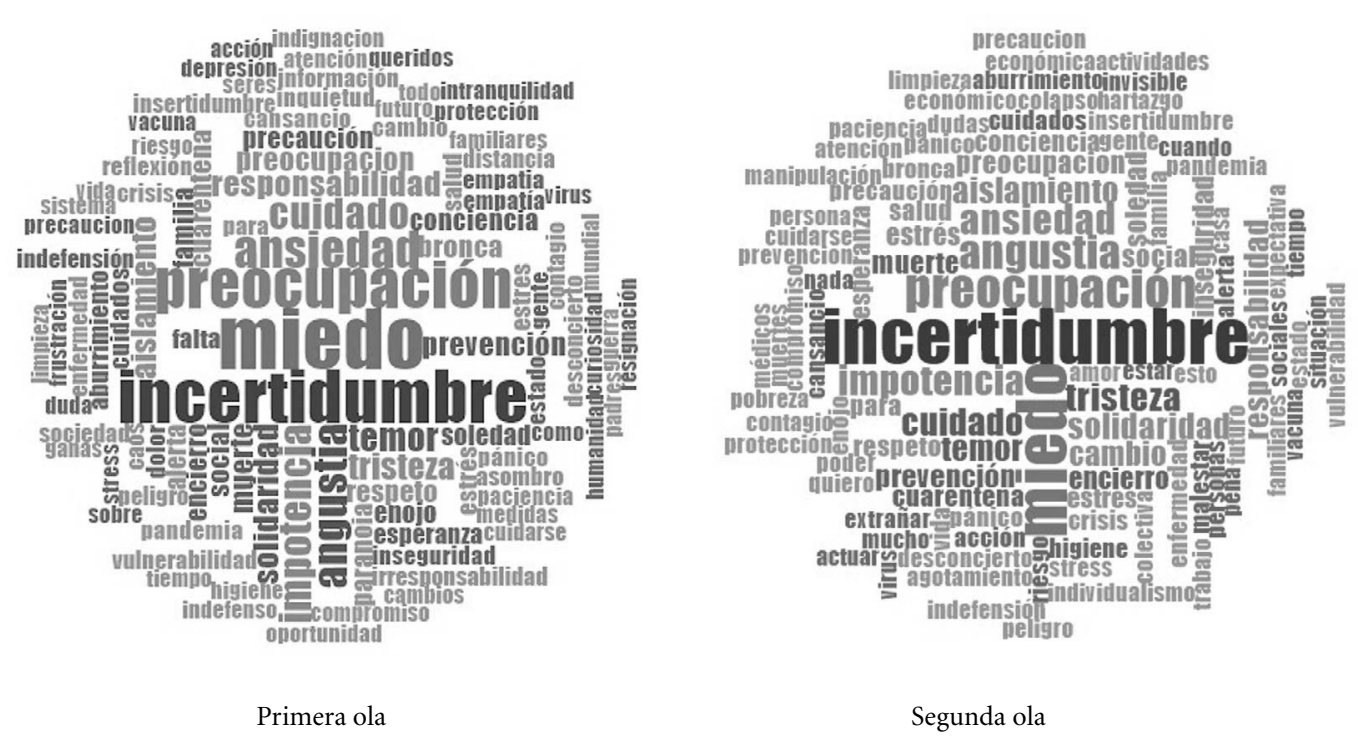

Gráfico 1. Nube de palabras sobre los sentimientos que genera en las personas el COVID-19. Argentina, 2020.

certidumbre, genera además en algunas personas un sentimiento de impotencia, resignación, desconcierto, de falta de control sobre la situación.

Por otro lado, la incertidumbre debe ser comprendida también vinculada a las consecuencias sociales y económicas que supone la medida del aislamiento para la vida cotidiana, social y laboral. En ese sentido, algunas personas expresaban: Extraño a mi familia y mi economía está muy mal (Ola 1, hombre, 57 años); Incertidumbre econó- mica, preocupación por familiares, caída laboral (Ola 2, hombre, 43 años).

Así mismo el Miedo aparece como segundo subtema relevante ambas olas de la encuesta. Este sentimiento se expresó en un gradiente que incluía desde expresiones de temor, ansiedad, hasta pánico por parte de algunas personas, aspecto que también se vincula a efectos en el bienestar integral de las personas encuestadas. Así algunas personas solo pudieron responder esta pregunta 


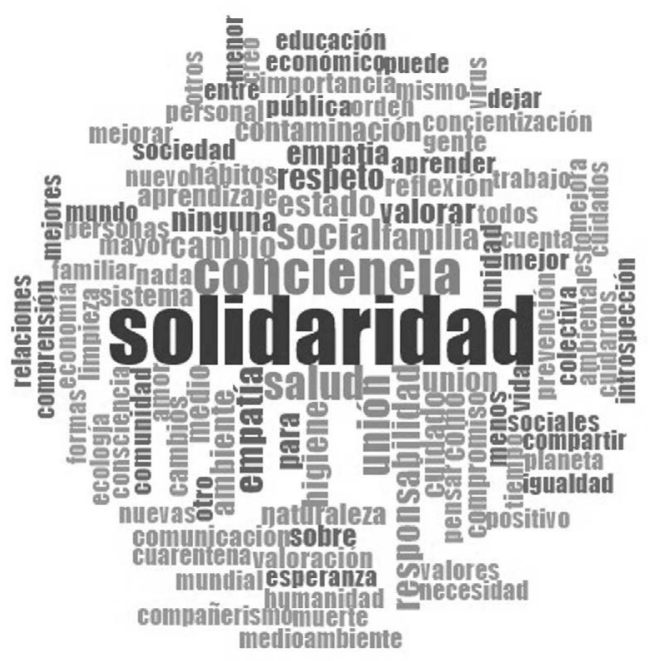

Primera ola

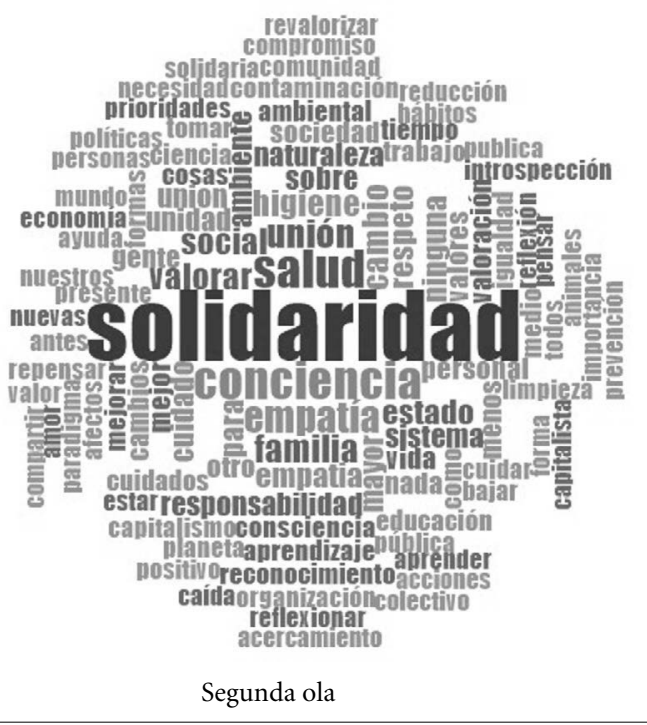

Gráfico 2. Nube de palabras sobre las consecuencias positivas que podría tener el COVID-19. Argentina, 2020.

con la palabra miedo y temor, y otras personas sólo sentimientos asociados al miedo en su respuesta: Temor, nerviosismo, peligro (Ola 1, mujer, 48 años):Pánico, miedo al contagio (Ola 2, mujer, 27 años). También se expresó miedo por la salud de personas cercanas: Miedo y terror a que adquieran la enfermedad mis padres (Ola 1, mujer, 26 años) y algunas personas en grupos de riesgo explicaron su miedo en relación a dicho factor: Me siento asustada, soy mayor y tomo inmunosupresores (Ola 1, mujer, 60 años). Observamos que el miedo tiene mayor preeminencia entre quienes tienen menor nivel educativo, en las dos tomas de datos, y aumenta entre las personas con nivel educativo alto en el segundo momento de toma de datos. En ese mismo sentido, en ambas tomas de datos, podemos observar que quienes reportan menos confort en sus hogares dicen con mayor frecuencia sentir miedo frente al COVID-19.

Cabe destacar que los sentimientos de Incertidumbre, Miedo, Responsabilidad y Angustia, que constituyen las expresiones más relevantes entre las personas participantes, se manifestaron con mayor preeminencia entre las mujeres.

El sentimiento de Responsabilidad incluye la importancia de los cuidados y la responsabilidad individual y colectiva para prevenir el COVID-19. La creciente precaución frente a la enfermedad y la prevención, son aspectos claves que nombran algunas personas, independientemente de su ni- vel educativo en ambas tomas de datos: "Respeto. Conocimiento. Cuidado" (Ola 1, mujer, 54 años). La forma en que el virus se propaga, exige un mayor registro del propio cuerpo, por ejemplo, con en el lavado de manos y también respecto al cuerpo de las otras personas, especialmente en lo relacionado con evitar el contacto y mantener la distancia. Ello se traduce, por un lado, en respeto y cuidado hacia los demás, especialmente de quienes pueden estar en una posición más vulnerable frente al virus, pero también en el cuestionamiento de las conductas de algunas personas frente a las medidas de prevención, que son calificadas como irresponsabilidad, tal como da cuenta esta expresión: La incapacidad de mucha gente para respetar normas por un bien común superior. Egoísmo (Ola 1, mujer, 36 años). Este sentimiento de responsabilidad pone en manifiesto la incorporación de los discursos preventivos: Ser responsable, tomar medidas de prevención, aislamiento social (Ola 1, mujer, 37 años); Prevención, prudencia, responsabilidad (Ola 1, mujer, 55 años). Cabe señalar también que la brecha advertida en la primera ola de la encuesta entre mujeres y varones respecto al sentimiento de Responsabilidad, se reduce en la segunda ola. Respecto a la percepción de confort en su hogar ante la situación de aislamiento social, observamos que quienes perciben mayor confort mencionan más la importancia de la responsabilidad y los cuidados frente a la pandemia. 
La Angustia aparece e incluye sentimientos que van desde la tristeza, el aburrimiento, hasta la depresión. En ocasiones este sentimiento se vincula a otras personas, como por ejemplo los seres queridos, o hacia personas en situación de exclusión social: Angustia por familiares que deben ir a trabajar y por mi nieta que está en India y no puede volver (Ola 1, mujer, 71 años); Tristeza por los más desfavorecidos (Ola 1, hombre, 51 años).

La Soledad aparece vinculada al encierro y al aislamiento. En palabras de una participante: Aislamiento indefinido. Extrañar la rutina y a la familia (Ola 2, mujer, 19 años). Por otro lado, esta pandemia genera un sentimiento de Vulnerabilidad que se relaciona con la indefensión, la fragilidad, la inseguridad, la posibilidad de morir debido a una probable infección y también con la impotencia que ello genera. Ambos sentimientos estuvieron más presentes entre mujeres en ambos momentos, aunque la brecha es menor en la segunda ola. También se reducen en la segunda ola las brechas de género en las categorías de Angustia y Vulnerabilidad.

Con menor frecuencia, aparecen los sentimientos de Descontrol expresado como locura, crisis, caos y paranoia generados por la pandemia y de Enojo, en este caso vinculado a expresiones de bronca y hartazgo.

\section{Consecuencias positivas para la sociedad}

Este tema agrupa las opiniones de las personas participantes respecto a las consecuencias positivas para la sociedad que podría generar esta pandemia. A continuación, se desarrollan los subtemas principales identificados.

La Valorización de la Interdependencia, fue una de las consecuencias más destacadas por las personas participantes. En esta valorización y reconocimiento de las personas como seres sociales se destacan los valores de solidaridad, empatía, unión y conciencia social. Las expresiones analizadas dan cuenta de una tendencia a valorar positivamente los lazos sociales y comunitarios, que por un lado aparecen como una demanda de empatía y conciencia social para sostener las medidas sanitarias, y que la mayoría de las personas valora puede ser beneficiosa para la sociedad: Entender que nadie se salva solo. Si nos cuidamos y prevenimos se evitan más muertes (Ola 2, mujer, 37 años); Comunidad, mayor sentido de un cuidado entre pequeñas comunidades (Ola 2, hombre, 26 años); Unión de la sociedad (Ola 2, hombre, 57 años).

La oportunidad de Reflexión entendida como toma de conciencia, introspección tanto indivi- dual como colectiva es valorada muy positivamente: Crecer autoconciencia introspección (Ola 2, mujer, 46 años) y Reflexión, pensar, reconfigurar (Ola 2, hombre, 33 años). A la vez la reflexión se vincula con aprendizajes y crecimiento mediante las valoraciones reflexivas: Conocimiento personal, orden de prioridades para la vida diaria (Ola 1, mujer, 45 años). Las mujeres, valoran más la interdependencia y la reflexión como consecuencias positivas.

La Valorización del medio ambiente, entendido como la menor contaminación, cuidado a los animales y del ecosistema, pero también vinculado a un cambio de actitud de las personas respeto por la naturaleza (Ola 2, mujer, 45 años) conciencia medioambiental (Ola 2, mujer, 23 años):aparece como una consecuencia positiva de la pandemia, principalmente entre mujeres, participantes de mayor nivel educativo y entre quienes perciben mayor confort en su hogar.

Surgen también expresiones vinculadas con la Valoración del Estado y las Instituciones, que engloba el reconocimiento de un modelo de estado de bienestar, particularmente respecto a la salud pública, y en menor medida de la investigación: Reconocer el trabajo que hacen de los médicos diariamente y hoy más que nunca (Ola 1, mujer, 25 años). Poner en valor el Estado y la salud pública (Ola 1, mujer, 36 años). Al igual que en la valorización del medio ambiente, algunas personas enfatizan el cambio vinculado a la valorización del sistema sanitario y científico: Que la gente se concientice sobre la importancia de un estado presente y la inversión en salud, ciencia y educación (Ola 2, mujer, 40 años). En la primera ola, el grupo que en mayor medida expresó como consecuencia positiva la Valoración del Estado y las instituciones, tiene mayor nivel educativo $y$ perciben mayor confort en sus hogares. En la segunda ola, fueron los varones quienes adhirieron más a la Valorización del Estado y las Instituciones como consecuencia positiva para la sociedad.

Valorización de los afectos es otra consecuencia identificada, principalmente entre mujeres, que supone una puesta en valor de aquellos lazos cercanos: Valorar a la familia y amigos, unión entre personas (Ola 1, mujer, 24 años); Acercamiento a los seres queridos (Ola 2, mujer, 20 años). Observamos que entre quienes manifiestan mayor confort de su hogar valoran más esta consecuencia positiva.

La Revisión del sistema, engloba la mirada de quienes percibían cambios del sistema económico, laboral, educativo como consecuencia de la pandemia. Algunas expresiones incluso plantea- 
ron incluso cambios de paradigma más amplios y profundos: Revisión del modo de vida, solidaridad, cambio de paradigma (Ola 2, hombre, 57 años). Se refieren además a modificaciones vinculadas a los modos de producción a un nuevo orden económico: Sobre la producción de los alimentos en la huerta, organización en el hogar (Ola 1, mujer, 25 años):también a lógicas laborales: Redefinición de lógicas laborales, interrogación sobre el lugar del lazo social en tiempos de lo virtual (Ola 2, hombre, 26 años) y Cambios en la comunicación entre personas (Ola 1, mujer, 48 años). Destaca que la oportunidad de revisar el sistema social es valorada como positiva especialmente entre las personas de mayor nivel educativo y que perciben mayor confort en su hogar.

Surgen también, con menor énfasis, consecuencias vinculadas a una mayor Limpieza e Higiene en nuestra sociedad. Estas expresiones se relacionan con las medidas de prevención del COVID-19 que suponen un cambio de hábitos: Muchas personas aprenderán de la importancia de la higiene de las manos (Ola 1, mujer, 30 años). Mayor Control y responsabilidad social expresa actitudes de obediencia, cumplimiento de normas y orden, como consecuencias positivas para algunas personas participantes: Orden, respeto (Ola 1, mujer, 59 años); Respeto a las reglas (Ola 2, mujer, 58 años). Se destaca que es una de las consecuencias positivas más presente entre participantes de mayor nivel educativo. En la segunda toma de datos, disminuyó la tendencia a valorar de forma positiva el control y la responsabilidad como también la limpieza y la higiene. Por último, algunas personas señalaron que no había Ninguna consecuencia positiva derivada de la pandemia.

\section{Discusión}

El estudio realizado da cuenta de efectos subjetivos y emocionales en la primera etapa de la pandemia en Argentina. Se advierte un impacto en la salud mental, expresado en sentimientos de miedo, incertidumbre y angustia, propios de un sentido de ruptura en la cotidianidad y pérdida de previsibilidad que supone esta pandemia, especialmente el aislamiento que conlleva. Sin embargo, también se revelan otros aspectos valorados como positivos para la sociedad, como un sentido de responsabilidad y cuidado, así como la interdependencia de las personas y la posibilidad de reflexión tanto sobre sí mismos y como sociedad.
Nuestros resultados señalan una alta incertidumbre y miedo de la población estudiada en relación al COVID-19. Similarmente, en la India, un estudio destaca el alto porcentaje de personas que expresaron preocupación e incertidumbre frente al COVID-19 (80\%) y un porcentaje aún mayor que señala la necesidad de contar con apoyo profesional para reducir el impacto en su salud mental ${ }^{16}$.

Desde un paradigma conductista Harper et al. ${ }^{17}$ comprenden al miedo como una respuesta adaptativa ante un peligro real, como el COVID-19, que incluso parece asociarse a cambio de hábitos que protegen la salud. Desde otro marco teórico, Mamzer ${ }^{18}$ advierte que el COVID-19 y las medidas para prevenirlo se presentan como disruptores del sentido de seguridad ontológica, que permitía a las personas organizar su cotidianidad hasta ese momento, generando sentimientos negativos como el miedo, que pueden agravarse según la persistencia y el desarrollo del virus. En efecto, en epidemias precedentes como la del Ébola, el impacto del miedo fue clave para aumentar el impacto en la salud mental y problemas sociales ${ }^{19}$, por lo que debería tenerse en cuenta.

Los resultados obtenidos no sólo expresan consecuencias negativas de la pandemia en las emociones, en lo afectivo y vincular, sino que evidencian una mirada más amplia sobre el sistema social y político, donde las personas encuestadas por un lado perciben posibles cambios que también se vinculan a su posición en la estructura social. La percepción sobre posibles consecuencias positivas para la sociedad, permitió conocer cómo el impacto subjetivo de la pandemia se articula con una mirada más macro de la situación, que involucra órdenes económicos, políticos y sociales.

La valorización de la interdependencia y los sentimientos de empatía, solidaridad y conciencia social, aparecen como una constante que sólo varía en su percepción de acuerdo al género. Se ha señalado que estos sentimientos de altruismo deben ser promovidos en contextos de aislamiento preventivo para disminuir el impacto en la salud mental ${ }^{6}$. Lo mismo se puede advertir con la actitud de reflexión, que es generalizada, aunque expresada en mayor medida en mujeres.

Asimismo, la valoración del Estado y sus instituciones se puede interpretar también como una percepción y evaluación del papel del Estado argentino frente a la crisis sanitaria que genera el COVID-19, y las medidas y políticas públicas tomadas. De alguna manera es posible encontrar 
vinculaciones entre el sentimiento de miedo y la idea de solidaridad y de lo común en un contexto disruptivo. Como sugiere $\mathrm{Ahmed}^{20}$ siguiendo a Ulrich Beck en las sociedades modernas la solidaridad suele basarse en la percepción del riesgo compartido, y en Argentina estas emociones se han movilizado hacia la solidaridad en una primera instancia.

En cuanto a aquellas posiciones que evalúan el control y el orden como aspectos positivos del COVID-19, podrían vincularse a que el sostenimiento de las medidas de prevención, especialmente el aislamiento, genera una mayor responsabilidad por parte de la población. Esto podría pensarse con lo que Davis et al. ${ }^{21}$ proponen al analizar la noción de inmunidad como categoría biológica y política. Por un lado, evidencian las transformaciones que un virus produce en la percepción de los propios límites corporales de los individuos como en su conexión otras personas. En este sentido, así como el virus puede activar dispositivos de control vinculados a la responsabilización individual, que los autores denominan "inmunidad elegida", y también suponen una demanda de control por parte del Estado $^{21}$. Siguiendo a Ahmed ${ }^{20}$ las fronteras y las defensas de la nación son como la piel y funcionan como metáfora al poner en tensión la proximidad de los otros.

Por otro lado, las diferencias sociales en la población, respecto al nivel educativo y el confort percibido durante el aislamiento social, y el género, constituyen indicadores que dan cuenta la desigualdad de recursos culturales y materiales en el marco de la crisis sanitaria y especialmente en el impacto diferencial en la salud mental que provoca una pandemia ${ }^{22}$, como la actual. Por ejemplo, nuestros resultados indican que el sentimiento de miedo se expresa en mayor medida en aquellas personas encuestadas con un menor nivel educativo, así como en aquellas que perciben menor comodidad en sus hogares durante el aislamiento preventivo, desde la primera toma de datos. Asimismo, aspectos como la revalorización del medio ambiente y la posibilidad de revisar y replantear el sistema social y económico, aparecen como escenarios positivos para las personas de nivel educativo universitario. Manstead ${ }^{23} \mathrm{ex}^{-}$ plica cómo la clase social influencia en las percepciones y menciona que las personas que están en desventaja por un sistema social suelen, paradójicamente, ser quienes menos lo cuestionan o rechazan. Estos sectores objetivamente enfrentan mayores niveles de amenaza, vinculado a una menor seguridad en empleo, vivienda, salud, que podría contribuir a comprender el mayor miedo observado en nuestros resultados y la menor tendencia a cuestionarse en esta pandemia sobre aspectos más macro como el medio ambiente o el sistema socio-económico, que son probablemente percibidos como externos y alejados de su control.

Otro aspecto relevante en nuestros resultados está vinculado con el género. Fueron las mujeres participantes quienes manifestaron en mayor medida los sentimientos de miedo, angustia junto con sentimientos de responsabilidad, cuidados y valorización de la interdependencia, afectos y la posibilidad de introspección y reflexión que la pandemia generaría. Esto podría explicarse por la socialización de género, que vincula de forma diferencial a las mujeres con lo afectivo, los cuidados y la expresión de emociones mientras que la socialización de género masculina obstaculiza su expresión en determinados contextos ${ }^{24}$ resultado de guiones culturales heteronomativos que moldean los cuerpos de las personas ${ }^{20}$.

Una revisión previa apunta a que estas diferencias de género pueden verse también influenciadas por el contexto y sus presiones ${ }^{25}$ como podría ser la situación de pandemia. En ese sentido, podría comprenderse que los encuestados varones hayan manifestado más sus sentimientos de vulnerabilidad $y$ angustia en el segundo momento de toma de datos. Este resultado, podría indicar también que las consecuencias del aislamiento social en la vida de las personas pueden ser cada vez adversas si se mantienen en el tiempo.

Por otro lado, esta mayor expresión de miedo $y$ angustia que manifiestan las mujeres de nuestro estudio podría también estar dando indicios de que esta pandemia las afecta más particularmente. Ya la $\mathrm{ONU}^{26}$ ha destacado que las mujeres son las primeras respondientes frente a la crisis del COVID-19 en su rol de trabajadoras, voluntarias y cuidadoras, siendo por dicho rol, afectadas de forma desigual ya que asumen costos físicos y emocionales mayores, así como un mayor riesgo de infección en la respuesta a la pandemia. En el caso de Brasil ${ }^{27}$ también se observó que las mujeres perciben un mayor riesgo de contagio no sólo por un mayor sentido de autocuidado, sino por la feminización del sector salud. Del mismo modo la Organización de Naciones Unidas ${ }^{28}$ también ha señalado cómo el aislamiento puede tener efectos adversos respecto violencia basada en razones de género. Este estudio presenta algunas limitaciones que cabe mencionar. En primer lugar, en la muestra lograda predomina un alto nivel educativo y buena salud percibida. Asimismo, también 
destaca la mayor participación de personas de una provincia del país, desde donde se lanzó la encuesta. Estas limitaciones podrían estar vinculadas a que la encuesta fue distribuida de manera online, y no todas las personas tienen acceso a internet y a tecnologías, especialmente aquellas de los sectores más desfavorecidos de nuestra sociedad. Todos estos aspectos deben considerarse en próximos estudios, con el objetivo de alcanzar representatividad de diversos sectores sociales. Asimismo, se reconoce necesario profundizar en los significados subjetivos que las personas han comentado en el cuestionario, a través de técnicas cualitativas que permitan indagar los porqués de dichos sentimientos.

\section{Conclusiones}

Este trabajo permitió conocer los sentimientos de las personas frente al COVID-19 en Argentina. En términos generales, en las fases iniciales de la pandemia en Argentina se observa un impacto en la salud mental de las personas en el que se destacan el miedo, la incertidumbre y la angustia. Sin em- bargo, emerge también un sentido de responsabilidad y cuidado junto con la puesta en valor de la dimensión social de las personas y la posibilidad de reflexionar que otorgaría como consecuencia positiva la situación de aislamiento social.

Nuestros resultados señalan la importancia de considerar el impacto de las políticas públicas, especialmente del aislamiento social, frente a la pandemia en la dimensión afectiva y vincular de las personas. Así mismo, resaltan la necesidad de diseñar estrategias para disminuir la incertidumbre con el objetivo de mejorar la salud de la población, considerando las desigualdades sociales y de género existentes. Por otro lado, la solidaridad, la conciencia social y la empatía entendidas como consecuencias positivas del COVID-19 en la población, podrían ser valores que contribuyan a la aceptación y al cumplimiento de medidas de prevención, reduciendo probablemente el impacto en la salud mental. Así, estos resultados podrían contribuir al diseño de medidas para afrontar la pandemia del COVID-19 y sus consecuencias en Argentina, atendiendo al cuidado de la salud de la población desde una perspectiva integral.

\section{Colaboradores}

MC Johnson y L Saletti-Cuesta diseñaron las preguntas incluidas en el cuestionario, analizaron e interpretaron los datos obtenidos y escribieron el primer borrador del texto. N Tumas contribuyó en el diseño del cuestionario, confeccionó la muestra y realizó el análisis cuantitativo de los datos. Todas las autoras realizaron contribuciones importantes, revisaron y aprobaron el texto final.

\section{Agradecimientos}

Agradecemos los aportes de Dra. Silvina Berra y Dr. Adrián Carbonetti en el diseño del estudio y del cuestionario utilizado. También al personal de apoyo de nuestro lugar de trabajo que colaboró en la difusión del cuestionario. Agradecemos muy especialmente a las personas participantes por su tiempo y contribución.

\section{Referencias}

1. Alocución de apertura del Director General de la OMS en la rueda de prensa sobre la COVID-19. Organización Mundial de la salud. [Declaración en internet] 2020. 11 de marzo. [acceso 2020 Abr 15] Disponible en: https://www.who.int/es/dg/speeches/ detail/who-director-general-s-opening-remarks-atthe-media-briefing-on-covid-19---11-march-2020

2. Taylor S. The Psychology of Pandemics: Preparing for the Next Global Outbreak of Infectious Disease. Cambridge: Cambridge Scholars Publishing; 2019.

3. World Health Organization (WHO). Mental health and psychosocial considerations during the COVID-19 outbreak, 18 Abril 2020. World Health Organization. [acceso 2020 Abr 15]. Disponible: https://apps.who. int/iris/handle/10665/331490.

4. Argentina. Ministerio de la Salud (MS). COVID-19 Recomendaciones para la asistencia y continuidad de la atención ambulatoria en salud mental durante la pandemia. 1 de Abril de 2020. [acceso 2020 Abr 12] Disponible en: http://www.msal.gob.ar/images/stories/ bes/graficos/0000001885cnt-covid-19_recomendaciones-asistencia-atencion-ambulatoria-salud-mental.pdf 
5. Stankovska G, Memedi I, Dimitrovski D. Coronavirus COVID-19 Disease, mental Health and Psychosocial Support. Society Register 2020; 4(2):33-48.

6. Brooks SK, Webster RK, Smith LE, Woodland L, Wessely S, Greenberg N, Rubin G. J. The psychological impact of quarantine and how to reduce it: rapid review of the evidence. Lancet 2020; 395(10227):912-920.

7. Wang C, Pan R, Wan X, Tan Y, Xu L, Ho CS, Ho RC. Immediate psychological responses and associated factors during the initial stage of the 2019 coronavirus disease (COVID-19) epidemic among the general population in China. Int J Environ Res Public Health 2020; 17(5):1729.

8. Shigemura J, Ursano RJ, Morganstein JC, Kurosawa M, Benedek DM. Public responses to the novel 2019 coronavirus (2019UnCoV) in Japan: mental health consequences and target populations. Psychiatry Clin Neurosci. No prelo 2020.

9. Inchausti F, MacBeth A, Hasson-Ohayon I, Dimaggio G. Psychological intervention and COVID-19: what we know so far and what we can do. 2020. [accesado 2020 Abr 10]. Disponible en: https://www. researchgate.net/profile/Felix_Inchausti/publication/340377032_Psychological_intervention_and_ COVID-19_What_we_know_so_far_and_what_ we_can_do/links/5e85a36792851c2f52745b66/ Psychological-intervention-and-COVID-19-Whatwe-know-so-far-and-what-we-can-do.pdf

10. Dong L, Bouey J. Public mental health crisis during COVID-19 pandemic, China. Emerg Infect Dis 2020; 26(7).

11. Duan L, Zhu G. Psychological interventions for people affected by the COVID-19 epidemic. Lancet Psychiatry 2020; 7(4):300-302.

12. Ho CS, Chee CY, Ho RC. Mental health strategies to combat the psychological impact of COVID-19 beyond paranoia and panic. Ann Acad Med Singapore 2020; 49(1):1-3.

13. Organización Panamericana de la Salud (OPAS). Unidad de Salud Mental y Uso de Sustancias (OPS/OMS). Protección de la salud mental y atención psicosocial en situaciones de epidemias. 2016. [accesado 2020 Abr 8]. Disponible en: https://www.paho.org/disasters/index. php?option=com_docman\&view=download\&category_slug=informes-tecnicos\&alias=2539-proteccion-salud-mental-atencion-psicosocial-situaciones-epidemias-2016-539\&Itemid $=1179 \&$ lang=en

14. WHO Regional Office for Europe. COVID-19 Snapshot Monitoring (COSMO): Monitoring knowledge, risk perceptions, preventive behaviours, and public trust in the current coronavirus outbreak. København: WHO Europe 2020.

15. Hsieh HF, Shannon SE. Three approaches to qualitative content analysis. Qual Health Res 2005; 15(9):1277-1288.

16. Roy D, Tripathy S, Kar SK, Sharma N, Verma SK, Kaushal V. Study of knowledge, attitude, anxiety \& perceived mental healthcare need in Indian population during COVID-19 pandemic. Asian J Psychiatr 2020; 102083.
17. Harper CA, Satchell L, Fido D, Latzman R. Functional fear predicts public health compliance in the COVID-19 pandemic. PsyArXiv [Periódico en internet] 2020 Abril [acceso 2020 Abr 15]. Disponible en: https://psyarxiv.com/jkfu3/

18. Mamzer H. Postmodern Society and COVID-19 Pandemic: old, new and scary. Society Register 2020; 4(2):7-18.

19. Shultz JM, Cooper JL, Baingana F, Oquendo MA, Espinel Z, Althouse BM, Mazurik L. The role of fear-related behaviors in the 2013-2016 West Africa Ebola virus disease outbreak. Curr Psychiatry Rep 2016; 18(11):104.

20. Ahmed S. La politica cultural de las emociones. México: Universidad Nacional Autónoma de México, Programa Universitario de Estudios de Género; 2015.

21. Davis M, Flowers P, Lohm D, Stephenson N. Immunity, biopolitics and pandemics: Public and individual responses to the threat to life. Body Soc 2016; 22(4):130-154.

22. Perrin PC, McCabe OL, Everly GS, Links JM. Preparing for an influenza pandemic: mental health considerations. Prehosp Disaster Med 2009; 24(3):223-230.

23. Manstead AS. The psychology of social class: How socioeconomic status impacts thought, feelings, and behaviour. Br J Soc Psychol 2018; 57(2):267-291.

24. De Boise S, Hearn J. Are men getting more emotional? Critical sociological perspectives on men, masculinities and emotions. Sociol Rev 2017; 65(4):779-796.

25. Wester SR, Vogel DL, Pressly PK, Heesacker M. Sex differences in emotion: A critical review of the literature and implications for counseling psychology. Couns Psychol 2002; 30(4):630-652.

26. Organización de las Naciones Unidas (ONU). COVID-19 en América Latina y el Caribe: cómo incorporar a las mujeres y la igualdad de género en la gestión de la respuesta a la crisis. Brief v.1.1, 2020. [acceso 2020 Abr 15]. Disponible en: https://lac.unwomen.org/es/ digiteca/publicaciones/2020/03/covid-como-incorporar-a-las-mujeres-y-la-igualdad-de-genero-en-lagestion-de-respuesta

27. Lima DLF, Dias AA, Rabelo RS, Cruz ID, Costa SC, Nigri FMN, Neri JR. COVID-19 no Estado do Ceará: Comportamentos e crenças na chegada da pandemia. Cien Saude Colet 2020; 25(5):1575-1586.

28. World Health Organization (WHO). Gender and Health in Natural Disasters. Adapted from: Gender and Health in Disasters. Geneva: WHO; 2002.

Artículo presentado en 18/04/2020

Aprobado en 22/04/2020

Versión final presentada en 24/04/2020 